\title{
Tonsillectomy as Treatment for Periodic Fever, Aphthous Stomatitis, Pharyngitis, and Cervical Adenitis Syndrome
}

\author{
Taniguchi K' ${ }^{\text {, Sakai }}{ }^{2}$, Ichiyama $\mathbf{Y}^{3}$, Yamamoto $\mathrm{H}^{4}$, Uemichi $\mathrm{K}^{5}$
}

\begin{abstract}
Although the etiology of periodic fever, aphthous stomatitis, pharyngitis, and cervical adenitis (PFAPA) syndrome remain unclear, various treatments have been reported. We here describe two thought-provoking cases. Our experience suggests that tonsillectomy is effective against PFAPA syndrome, and can safely be performed in patients three years and older. We recommend that tonsillectomy be considered as early as possible in patients with PFAPA syndrome.
\end{abstract}

Key words: Tonsillectomy, PFAPA syndrome.

\section{Introduction}

$\mathrm{P}$ eriodic fever, aphthous stomatitis, pharyngitis, and cervical adenitis (PFAPA) syndrome is characterized by periodic high fever lasting three to six days and recurring regularly every two to eight weeks. The fever is associated with aphthous stomatitis, pharyngitis, and cervical adenitis ${ }^{1,2,3,4}$. Although the cause and etiology of PFAPA syndrome remain unclear, almost all cases spontaneously resolve about eight years after the onset of symptoms ${ }^{4}$.

Some clinicians have treated PFAPA syndrome with oral prednisolone and cimetidine until spontaneous remission ${ }^{5,6,7}$. Others have reported that tonsillectomy is an effective treatment ${ }^{8,9,10,11,12}$. Tonsillectomy has not become widely popular as a treatment for PFAPA syndrome because its effectiveness against PFAPA syndrome remains controversial. Furthermore, for safety reasons (to avoid postoperative complications), tonsillectomy is generally recommended for patients aged three years and older ${ }^{13}$, whereas oral medications can be used in younger patients.

We herein report on two patients with PFAPA syndrome. Tonsillectomy completely eliminated febrile attacks in both cases, suggesting that tonsillectomy is an effective treatment for PFAPA syndrome. Tonsillectomy was safely performed without postoperative complications in these patients aged three years and older.

\section{The Cases}

All procedures followed were in accordance with the ethical standards of the responsible committee on human experimentation (Tara Town Hospital, Japan) and with the Helsinki Declaration of 1975, as revised in 2013. Written informed consent for inclusion in this study was obtained from the parents of both children.
${ }^{1}$ Dr. Kazuto Taniguchi, MD, PhD, ${ }^{2}$ Dr. Tatsuya Sakai, MD, ${ }^{3} \mathrm{Dr}$. Yasunobu Ichiyama, MD, ${ }^{4}$ Dr. Hirokazu Yamamoto, MD, ${ }^{5}$ Dr. Kazuyasu Uemichi, MD. All from the Tara Town Hospital, 1520-12 Tara, Saga, 849-1602, Japan.

\section{Address for correspondence \\ Dr. Kazuto Taniguchi \\ E-mail: tgene1@po.hagakure.ne.jp}

\section{How to cite}

Taniguchi K, Sakai T, Ichiyama Y, Yamamoto $\mathrm{H}$, Uemichi K. Tonsillectomy as Treatment for Periodic Fever, Aphthous Stomatitis, Pharyngitis, and Cervical Adenitis Syndrome. J Nepal Paediatr Soc 2017;37(1):101-103.

doi: http://dx.doi.org/10.3126/jnps.v37i1.16683

This work is licensed under a Creative Commons Attribution 3.0 License.

\section{(c) (i)}


Case 1: A six-years-age boy with an unremarkable medical history experienced periodic febrile attacks accompanied by aphthous stomatitis, pharyngitis, and cough every two to eight weeks (Table 1). He was diagnosed with PFAPA syndrome in accordance with the diagnostic criteria advocated by Thomas et al. ${ }^{3}$ at three years of age, although the onset of disease was at one year of age. During febrile attacks, prednisolone (single dose of $0.5 \mathrm{mg} / \mathrm{kg}$, repeated in 12 hours if necessary, depending on response to treatment) effectively reduced the fever. The patient underwent tonsillectomy at the age of six years. No postoperative complications occurred. He has not experienced a febrile attack for more than 20 months since tonsillectomy.

Case 2: A three-years-age girl with an unremarkable medical history experienced periodic febrile attacks accompanied by aphthous stomatitis and pharyngitis every two to seven weeks (Table 1). She was diagnosed with PFAPA syndrome at the age of one year in accordance with the criteria of Thomas et al. ${ }^{3}$ During febrile attacks, prednisolone (a single dose of $0.5 \mathrm{mg} / \mathrm{kg}$, repeated in 12 hours if necessary, depending on response to treatment) effectively reduced the fever. The patient tried cimetidine once; however, she could not tolerate the medication because of its bitter taste. She underwent tonsillectomy at the age of three years. No postoperative complications occurred. She has not suffered from a febrile attack for more than five months since tonsillectomy.

Pathological examination in both cases revealed the findings of chronic tonsillitis, including enlarged and hyperplastic lymphoid follicles (Data not shown).

\section{Discussion}

The courses of these patients illustrate two important clinical issues.

First, tonsillectomy completely eliminated febrile attacks in these patients, suggesting that tonsillectomy is a highly effective treatment for PFAPA syndrome. Previous studies have reported that tonsillectomy is effective in $63 \%$ to $100 \%$ of patients with PFAPA syndrome $^{8,9,10,11,12}$. Tonsillectomy was an effective treatment in both of our patients.

Second, tonsillectomy was safely performed in our patients at the age of three years and older. Tonsillectomy is generally recommended for patients aged three years and older to avoid postoperative complications, in accordance with the clinical guideline ${ }^{13}$. Febrile attacks of PFAPA syndrome can begin as early as 1 month of age $\mathrm{e}^{1,3,11,14}$. Younger patients with PFAPA syndrome should wait until 3 years of age for tonsillectomy. Case 2 demonstrates that tonsillectomy can be performed in three years age patients without postoperative complications.

Differential diagnosis includes other periodic fever syndromes ${ }^{6}$. Several conditions can be different from PFAPA syndrome (Table 2). Familial Mediterranean fever (FMF) is characterized by recurrent fevers with stomatitis, abdominalgia, and thoracalgia. Hyper IgD syndrome is characterized by recurrent fevers with rash, arthralgia, and abdominalgia. Tumor necrosis factor-associated periodic syndrome (TRAPS) involves recurrent fevers, myalgia, abdominalgia, and rash. Our cases have not suffered from abdominalgia, thoracalgia,

Table 1: Characteristics of our two cases

\begin{tabular}{|c|c|c|c|c|}
\hline Case & Sex & Symptoms & Age at onset & Age at tonsillectomy \\
\hline \multirow{3}{*}{1} & \multirow{3}{*}{ Male } & High fever & \multirow{3}{*}{1 year } & \multirow{3}{*}{6 years } \\
\hline & & Pharyngitis & & \\
\hline & & Stomatitis, cough & & \\
\hline \multirow{3}{*}{2} & \multirow{3}{*}{ Female } & High fever & \multirow{3}{*}{1 year } & \multirow{3}{*}{3 years } \\
\hline & & Pharyngitis & & \\
\hline & & Stomatitis & & \\
\hline
\end{tabular}

Table 2: Major differential diagnosis of PFAPA syndrome

\begin{tabular}{ccccc}
\hline & FMF & Hyper IgD Syndrome & \multicolumn{1}{c}{ TRAPS } & Cyclic Neutropenia \\
\hline \multirow{2}{*}{ Associated } & Stomatitis & Rash & Myalgia & Stomatitis \\
\cline { 2 - 5 } Symptoms & Abdominalgia & Arthralgia & Abdominalgia & Pharyngitis \\
\cline { 2 - 5 } & Thoracalgia & Abdominalgia & Rash & \\
Steroid & Ineffective & Effective & Effective & Ineffective \\
\hline
\end{tabular}


myalgia, and rash. In cyclic neutropenia, neutropenic episodes are associated with recurrent fevers. Aphthous stomatitis and pharyngitis in cyclic neutropenia are similar to the lesions described in PFAPA syndrome. Although steroid including prednisolone is effective against PFAPA syndrome, it is ineffective against cyclic neutropenia. Our cases have not shown a decline in number of neutrophils and, prednisolone was effective in our cases.

We can also treat PFAPA syndrome with oral medications. Prednisolone is effective against the febrile attacks of PFAPA syndrome, although it shortens the interval between febrile attacks ${ }^{7}$. Cimetidine can reduce the febrile attacks of PFAPA syndrome ${ }^{3,4,7,15}$. Cimetidine is a common $\mathrm{H} 2$ antagonist that inhibits suppressor CD8+ T-lymphocyte activation and chemotaxis ${ }^{6,7}$.
Thomas et al. ${ }^{3}$, Feder et al. ${ }^{4}$, and Wurster et al. ${ }^{7}$ reported that cimetidine was effective in $43 \%, 27 \%$, and $24 \%$ of PFAPA patients, respectively. We previously proposed the use of cimetidine to reduce the febrile attacks of PFAPA syndrome until the age of 3 years, at which time tonsillectomy can be performed ${ }^{15}$.

\section{Conclusion}

Tonsillectomy is a highly effective treatment for PFAPA syndrome, and can be safely performed in patients aged three years and older. We recommend that tonsillectomy be considered as early as possible for patients with PFAPA syndrome aged three years and older. Further studies are needed to determine whether tonsillectomy can be a main therapeutic strategy for PFAPA syndrome.

\section{References}

1. Marshall GS, Edwards KM, Butler J, Lawton AR. Syndrome of periodic fever, pharyngitis, and aphthous stomatitis. J Pediatr 1987;110(1):43-6. DOI: 10.1016/ S0022-3476(87)80285-8.

2. Marshall GS, Edwards KM, Lawton AR. PFAPA syndrome. Pediatr Infect Dis J 1989;8(9):658-9.

3. Thomas KT, Feder HM Jr, Lawton AR, Edwards KM. Periodic fever syndrome in children. $J$ Pediatr 1999;135(1):15-21. DOI: 10.1016/S00223476(99)70321-5.

4. Feder HM, Salazar JC. A clinical review of 105 patients with PFAPA (a periodic fever syndrome). Acta Paediatr 2010;99(2):178-84. DOI: 10.1111/j.16512227.2009.01554.x.

5. Feder HM Jr. Cimetidine treatment for periodic fever associated with aphthous stomatitis, pharyngitis, and cervical adenitis. Pediatr Infect Dis J 1992;11(4):31821.

6. Pinto A, Lindemeyer RG, Sollecito TP. The PFAPA syndrome in oral medicine: differential diagnosis and treatment. Oral Surg Oral Med Oral Pathol Oral Radiol Endod 2006;102(1):35-9. DOI: 10.1016/j. tripleo.2005.12.023

7. Wurster VM, Carlucci JG, Feder HM Jr, Edwards KM. Long-term follow-up of children with periodic fever, aphthous stomatitis, pharyngitis, and cervical adenitis syndrome. J Pediatr 2011;159(6):958-64. DOI: 10.1016/j.jpeds.2011.06.004.

8. Galanakis E, Papadakis CE, Giannoussi E, Karatzanis $A D$, et al. PFAPA syndrome in children evaluated for tonsillectomy. Arch Dis Child 2002;86(6):434-5. DOI: 10.1136/adc.86.6.434.

9. Renko M, Salo E, Putto-Laurila A, Saxen H, et al. A randomized, controlled trial of tonsillectomy in periodic fever, aphthous stomatitis, pharyngitis, and adenitis syndrome. J Pediatr 2007;151(3):289-92. DOI: 10.1016/j.jpeds.2007.03.015.

10. Licameli G, Jeffrey J, Luz J, Jones D, et al. Effect of adenotonsillectomy in PFAPA syndrome. Arch Otolaryngol Head Neck Surg 2008;134(2):136-40. DOI: 10.1001/archoto.2007.7

11. Garavello W, Romagnoli M, Gaini RM. Effectiveness of adenotonsillectomy in PFAPA syndrome: a randomized study. J Pediatr 2009;155(2):250-3. DOI: 10.1016/j.jpeds.2009.02.038.

12. Peridis S, Pilgrim G, Koudoumnakis E, Athanasopoulos I, et al. PFAPA syndrome in children: a meta-analysis on surgical versus medical treatment. Int $J$ Pediatr Otorhinolaryngol 2010;74(11):1203-8. DOI: 10.1016/j. ijporl.2010.08.014.

13. Baugh RF, Archer SM, Mitchell RB, Rosenfeld RM, et al. Clinical practice guideline: tonsillectomy in children. Otolaryngol Head Neck Surg 2011;144(1 Suppl):S1-30. DOI: 10.1177/0194599810389949.

14. Tasher D, Somekh E, Dalal I. PFAPA syndrome: new clinical aspects disclosed. Arch Dis Child 2006;91(12):981-4. DOI: 10.1136/adc.2005.084731.

15. Taniguchi K, Ono N, Sakai $T$, Ichiyama $\mathrm{Y}$, et al. Response to cimetidine in a 1-year-old child with PFAPA syndrome. Turk $J$ Pediatr in press. 